\title{
ÍNDICE CLIMÁTICO DE CRESCIMENTO PARA GRAMÍNEAS FORRAgEIRAS NO ESTADO DE SÃO PAULO $\left({ }^{1}\right)$
}

\author{
MÁRIO JOSÉ PEDRO JÚNIOR( ${ }^{2,3}$ )
}

\begin{abstract}
RESUMO
Utilizou-se o índice climático de crescimento (ICC) para gramíneas forrageiras, com base em temperatura, radiação solar e relação entre evapotranspiração real e potencial, a fim de estimar a produção de matéria seca (TAMS) de capim-colonião, gordura, jaraguá e pangola através da seguinte equaçāo exponencial: ICC $=$ a EXP (b ICC), onde a e b são constantes que diferem para cada espécie. Determinou-se o índice climático médio mensal para 47 localidades paulistas e regiōes limítrofes. A variação espacial do índice para o inverno e para o verão é apresentada em forma de mapas. Os valores de ICC no inverno, período crítico, variaram de 0,1 a 0,15 na região central do Estado; no Norte e no Oeste, foram superiores a 0,15 e, na Serra da Mantiqueira, inferiores a 0,1 .
\end{abstract}

Termos de indexação: índice climático de crescimento, gramíneas forrageiras, capimcolonião, capim-gordura, capim-pangola e capim-jaraguá.

\section{ABSTRACT \\ CLIMATIC GROWTH INDEX FOR FORAGE GRASSES IN THE STATE OF SÃO PAULO (BRAZIL)}

The climatic growth index (ICC) for forage grasses, based on temperature, solar radiation and the ratio of actual to potential evapotranspiration, was used to estimate dry matter production (TAMS) for the following grasses: "colonião" (Panicum maximum Jacq), "gordura" (Melinis minutiflora Pal de Beauv), "jaraguá" (Hyparrhenia rufa (Ness) Stapf) and "pangola" (Digitaria pentzii Stent), using exponential equations: ICC = a EXP (b ICC), where $\mathbf{a}$ and $\mathbf{b}$ are constants which differ for each specie analised. The monthly mean climatic index was calculated for forty seven localities of the State of São Paulo and neighbours. Its spatial distribution considering summer and winter is shown as maps. ICC values during the critical season of the winter varied from 0.1 to 0.15 for the central part of the State; at the northern and western regions it is larger than 0.15 and at the "Mantiqueira" mountains it is less than 0.1 .

Index terms: climatic growth index, forage grasses.

\footnotetext{
(1) Recebido para publicação em 15 de fevereiro e aceito em 18 de maio de 1995.

(2) Seção de Climatologia Agrícola, Instituto Agronômico (IAC), Caixa Postal 28, 13001-970 Campinas (SP).

$\left({ }^{3}\right)$ Com bolsa de pesquisa do CNPq.
} 


\section{INTRODUÇÃo}

A atividade pecuária do Brasil central iniciou-se com a exploração extensiva e, até certo ponto, extrativa, de áreas de pastagens naturais ou subespontâneas formadas, principalmente, pelos capins jaraguá, gordura e batatais. Posteriormente, formaram-se pastagens, mas sem levar em conta, para a espécie de forrageira utilizada, fatores limitantes, como a adaptabilidade às condições edafoclimáticas locais (Abramides et al., 1984).

A produção das pastagens, principalmente no Estado de São Paulo, traduz-se por ciclos estacionais de alta e de baixa produção que coincidem com as épocas de verão e de inverno (Mattos e Pedreira, 1984), sendo um dos principais problemas encontrados pelos criadores a definição da estação de crescimento vegetativo das forrageiras, função da intensidade da seca e do frio, para melhor planejamento da necessidade de alimentação para o gado.

Entre os fatores ambientais que mais influenciam no crescimento das pastagens e no rendimento de matéria seca, destacam-se os seguintes: a radiação solar, temperatura do ar e temperatura e umidade do solo (Montserrat et al., 1989).

A influência desses parâmetros no crescimento de pastagens foi analisada por Fitzpatrick \& Nix (1970), que obtiveram relações entre a produção de matéria seca de forrageiras tropicais e temperadas e a radiação solar, temperatura do ar e a razão entre evapotranspiração real e potencial, para estimar a produtividade potencial de diferentes sistemas ecológicos na Austrália. Mota et al. (1981) testaram esses índices para pastagens naturais no Rio Grande do Sul, verificando que, nesse Estado, há boa potencialidade climática para o desenvolvimento de gramíneas e leguminosas temperadas, enquanto as leguminosas tropicais, durante os meses mais rigorosos do inverno, não encontram condições adequadas. Mais tarde, Mota (1991) calculou os índices climáticos mensais de crescimento para pastagens nativas em Pelotas (RS), verificando que o rendimento médio diário de matéria seca podia ser estimado através desse índice, permitindo avaliar a lotação animal e as quantidades de feno necessárias para suplementar a pastagem nativa.
Este trabalho objetivou avaliar a possibilidade de uso do índice climático de crescimento para algumas espécies forrageiras (colonião, pangola, jaraguá e gordura) e mostrar sua variação espacial no território paulista para regionalização do potencial climático de produção de matéria seca em função do clima.

\section{MATERIAL E MÉTODOS}

Utilizaram-se dados de produção de matéria seca de: capim-colonião (Panicum maximum Jacq); gordura var. cabelo-de-negro (Mellinis minutiflora Pal de Beauv); jaraguá (Hyparrhenia rufa (Ness) Stapf) e pangola var. Taiwan A-24 (Digitaria pentzii Stent) obtidos por Pedreira (1973) em Nova Odessa (SP) de 1966 a 1970.

Os dados meteorológicos relativos à temperatura do ar, à radiação solar e à precipitação pluvial, obtidos no posto agrometeorológico no Instituto de Zootecnia, em Nova Odessa, foram analisados para testar a viabilidade do uso do índice climático de crescimento (ICC) e avaliar a produção de matéria seca das forrageiras. Posteriormente, dados de 47 localidades paulistas e de regiões limítrofes, foram usados para fins de mapeamento.

Para o Rio Grande do Sul, o índice climático de crescimento para pastagem, com base em temperatura, radiação solar e a razão evapotranspiração real e potencial, proposto por Fitzpatrick e Nix (1970) e avaliado por Mota et al. (1981), foi utilizado para estimativa da produção de matéria seca, como se segue:

$$
\mathrm{ICC}=\mathrm{IL} . \mathrm{IT} . \mathrm{IH}
$$

onde

IL é o índice de luz; IT, o índice térmico, e IH, o índice hídrico.

O índice de luz foi calculado em função da radiação solar:

$$
\mathrm{IL}=1,0-\operatorname{EXP}(-3,5(\mathrm{Rs} / 750))
$$

onde

Rs, a radiação solar (cal/cm ${ }^{2}$.dia), foi estimada pelo número de horas de brilho solar, de acordo com Cervellini et al. (1966). 

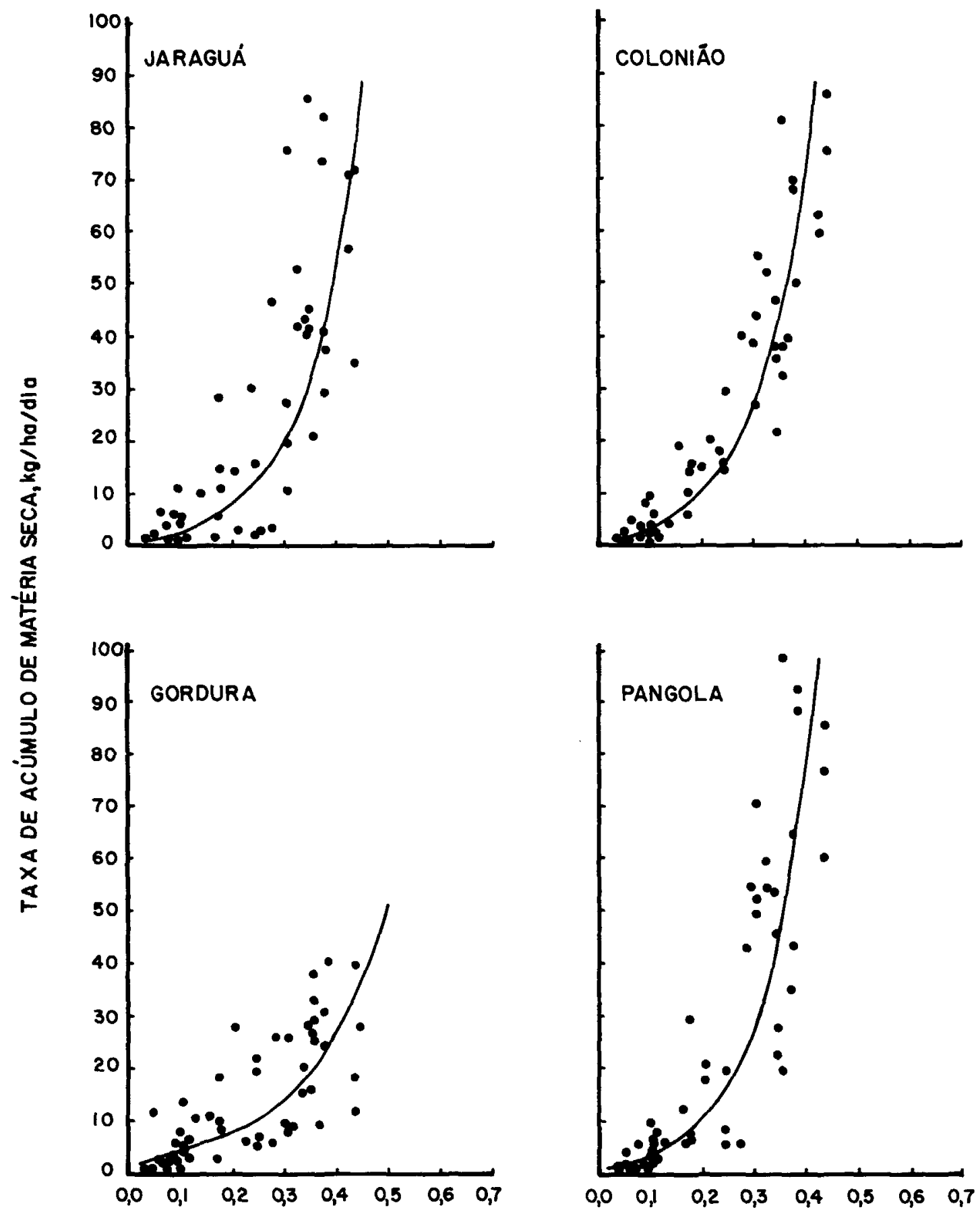

\section{INDICE CLIMÁTICO DE CRESCIMENTO}

Figura 1. Relação entre a taxa de acúmulo de matéria seca $(\mathrm{kg} / \mathrm{ha} / \mathrm{dia})$ de capim-jaraguá, colonião, gordura e pangola e o índice climático de crescimento para Nova Odessa (SP). Dados extraídos de Pedreira (1973). 
Calculou-se o índice térmico em funçāo das tabelas apresentadas por Mota et al. (1981) para gramíneas e leguminosas tropicais. Determinou-se o índice hídrico mediante o balanço hídrico segundo Thornthwaite \& Mather (1955), para armazenamento máximo de $125 \mathrm{~mm}$ de água no solo, usando a relação entre os valores mensais calculados da evapotranspiração real e potencial.

Os índices de luz, térmico e hídrico variam de 0 a 1; o índice climático de crescimento, portanto, também possui sua variação nessa faixa.

A relaçāo entre o índice climático de crescimento e a taxa de acúmulo de matéria seca (TAMS) em quilograma de matéria seca/hectare/dia foi analisada pela equação exponencial:

$$
\text { TAMS }=\mathrm{a} \operatorname{EXP}(\mathrm{b} \text { ICC })
$$

onde

a e b são constantes da equação de regressão para cada forrageira: capim-colonião, gordura, jaraguá e pangola. Verificada a viabilidade de uso do ICC como indicativo de potencialidade climática das regiões, na produção de matéria seca de forrageira, calculou-se esse índice para 47 localidades paulistas e regiões limítrofes para fins de mapeamento. Os dados de radiação solar estimada foram obtidos de Pedro Júnior et al. (1989).

Posteriormente, estabeleceram-se regressõcs lineares entre o valor do $\mathrm{ICC}$ de inverno e de verão, com a altitude dos locais analisados, objetivando o traçado das isolinhas para caracterização da variação espacial do índice climático de crescimento durante os períodos de verão e de inverno.

\section{RESULTADOS E DISCUSSÃO}

Índice climático de crescimento (ICC): este índice reflete o efeito composto da luz, temperatura e água disponível sobre o crescimento das pastagens tropicais e devem ser analisados em nível macroclimático (Fitzpatrick \& Nix, 1970) para valores médios, que admitem variações de ano para ano.

Para avaliar a influência do ICC na produção de matéria seca de espécies forrageiras, analisaram-se os valores médios mensais da taxa de acúmulo de matéria seca (TAMS), pela regressão exponencial em funçāo do índice climático de crescimento. Os valores obtidos referentes às constantes das equações encontram-se no quadro 1. A figura 1 expõe as curvas representativas e a variabilidade dos dados analisados. Os coeficientes de regressão obtidos foram: 0,$90 ; 0,88 ; 0,78$ e 0,76 , para colonião, pangola, jaraguá e gordura respectivamente (Quadro 1).

Utilizando dados meteorológicos de brilho solar, temperatura e chuva de diferentes localidades, calcularam-se os valores mensais dos índices de luz, térmico e hídrico e do ICC médio (Quadro 2).

Os valores do índice de luz obtidos foram da ordem de 0,75 no inverno e de 0,9 no verão, para a maioria das localidades analisadas, mostrando que o regime da radiação solar não chega a ser um fator limitante no crescimento das pastagens.

A maior limitação ao acúmulo de matéria seca, durante o inverno, nas regiões sul e montanhosas paulistas, deve-se ao regime térmico, apresentando valores baixos, cerca de 0,006 para Campos do Jordão e de 0,07 para Avaré. Nas regiōes Norte e Noroeste do Estado, a limitação maior é relativa ao regime hídrico, pois a relação entre a evapotranspiração real e a potencial (índice hídrico) atinge valores de 0,5 no inverno. No verão, quando as chuvas suplantam a necessidade de água das forrageiras, o índice hídrico atinge seu valor máximo $(1,0)$.

O valor do índice climático de crescimento mensal variou entre os extremos de: 0,005 a 0,106 para Campos do Jordão; 0,096 a 0,410 para Araçatuba c 0,101 a 0,495 no Vale do Ribeira (Quadro 2).

Quadro 1. Constantes da equação de regressão exponencial para estimativa da taxa de acúmulo de matéria seca (TAMS) em função do índice climático de crescimento (ICC), da forma TAMS = a EXP (b ICC), e coeficiente de correlação (r)

\begin{tabular}{lcrc}
\hline $\begin{array}{l}\text { Gramínea } \\
\text { forrageira }\end{array}$ & $\mathrm{a}$ & $\mathrm{b}$ & $\mathrm{r}$ \\
\hline Coloniāo & 1,46 & 9,67 & 0,90 \\
Jaraguá & 1,08 & 9,72 & 0,78 \\
Pangola & 1,26 & 10,29 & 0,88 \\
Gordura & 2,22 & 6,27 & 0,76 \\
\hline
\end{tabular}




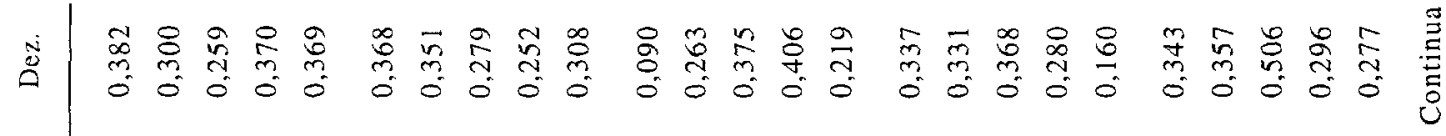

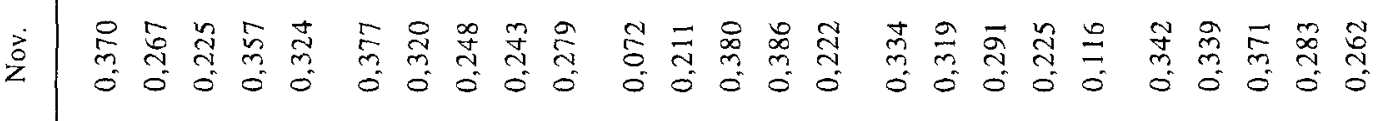

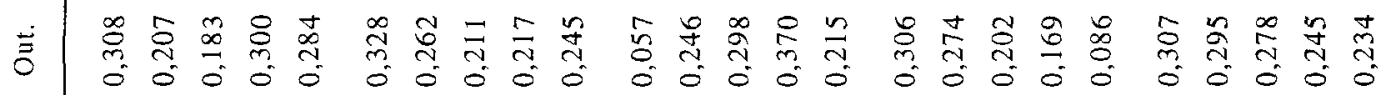

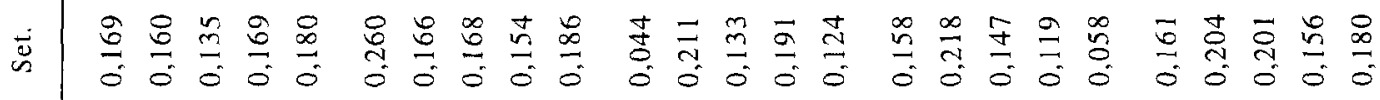

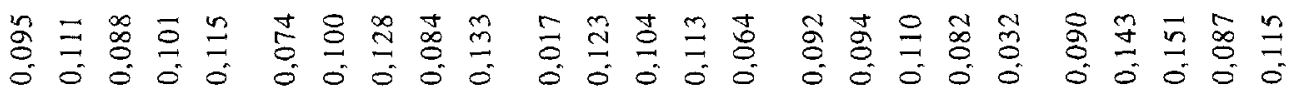

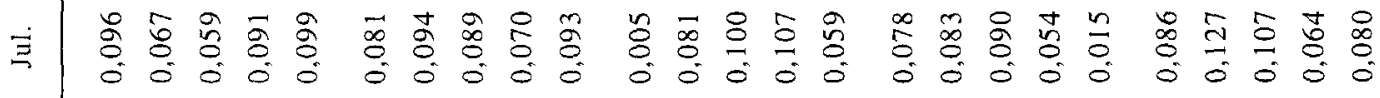

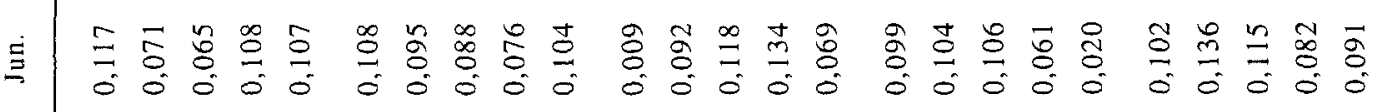

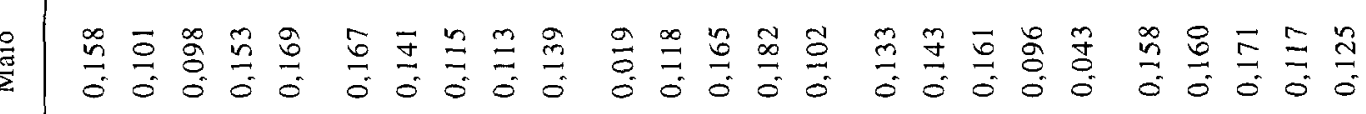

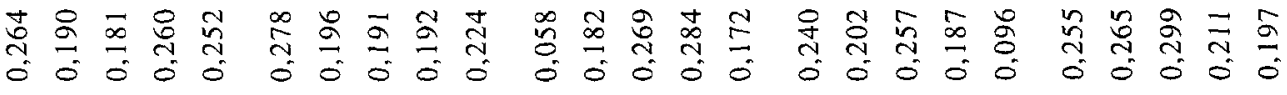

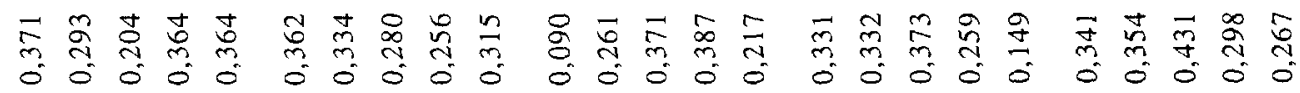

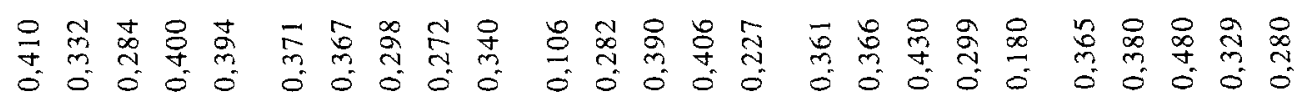

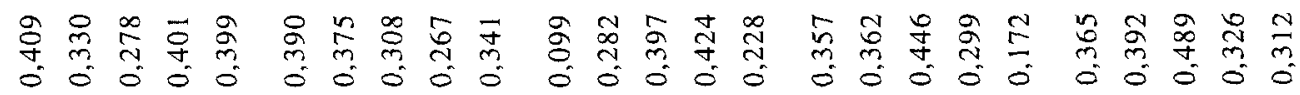

$\stackrel{\Xi}{\Xi}$ 


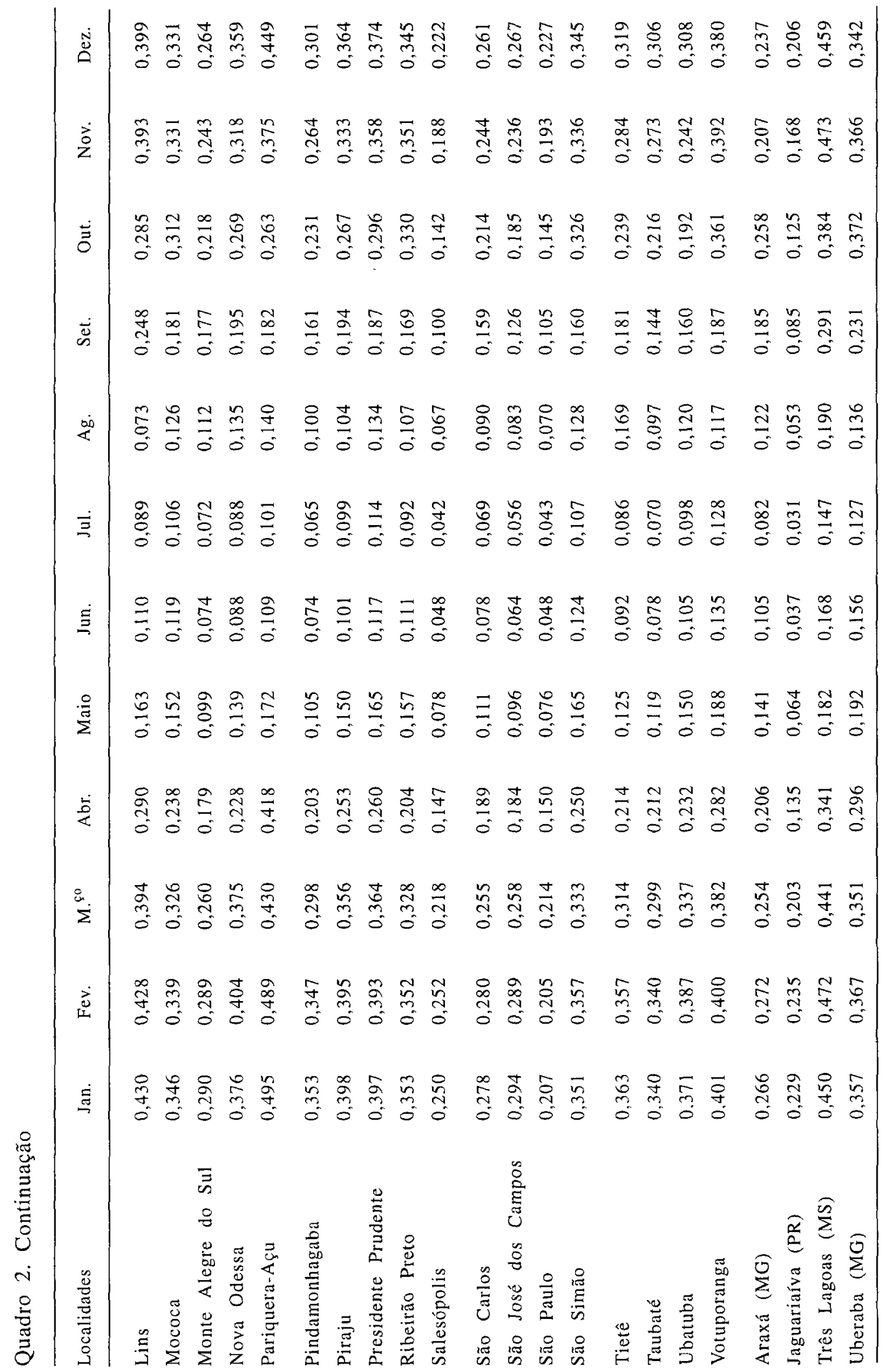




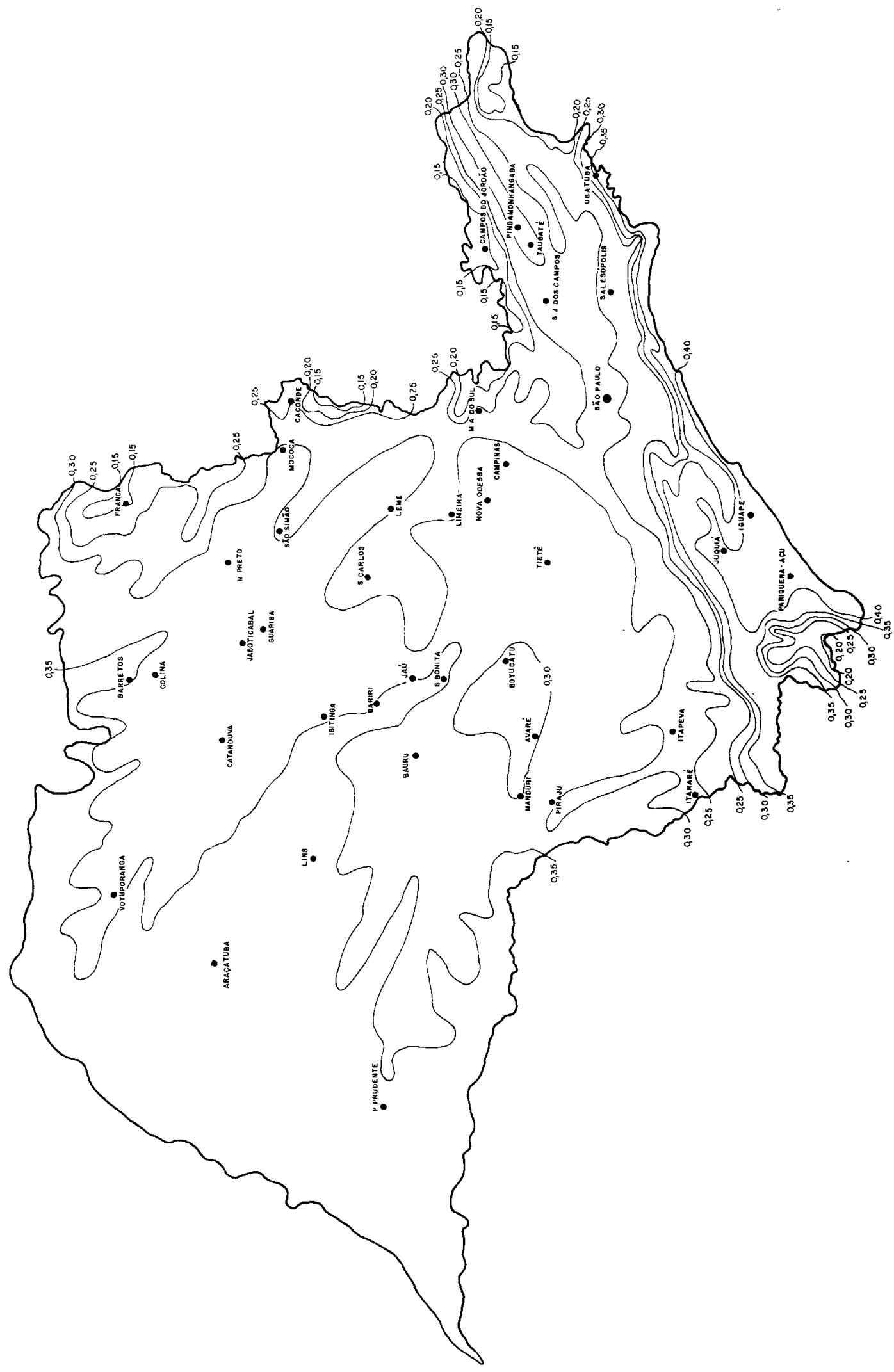

完 


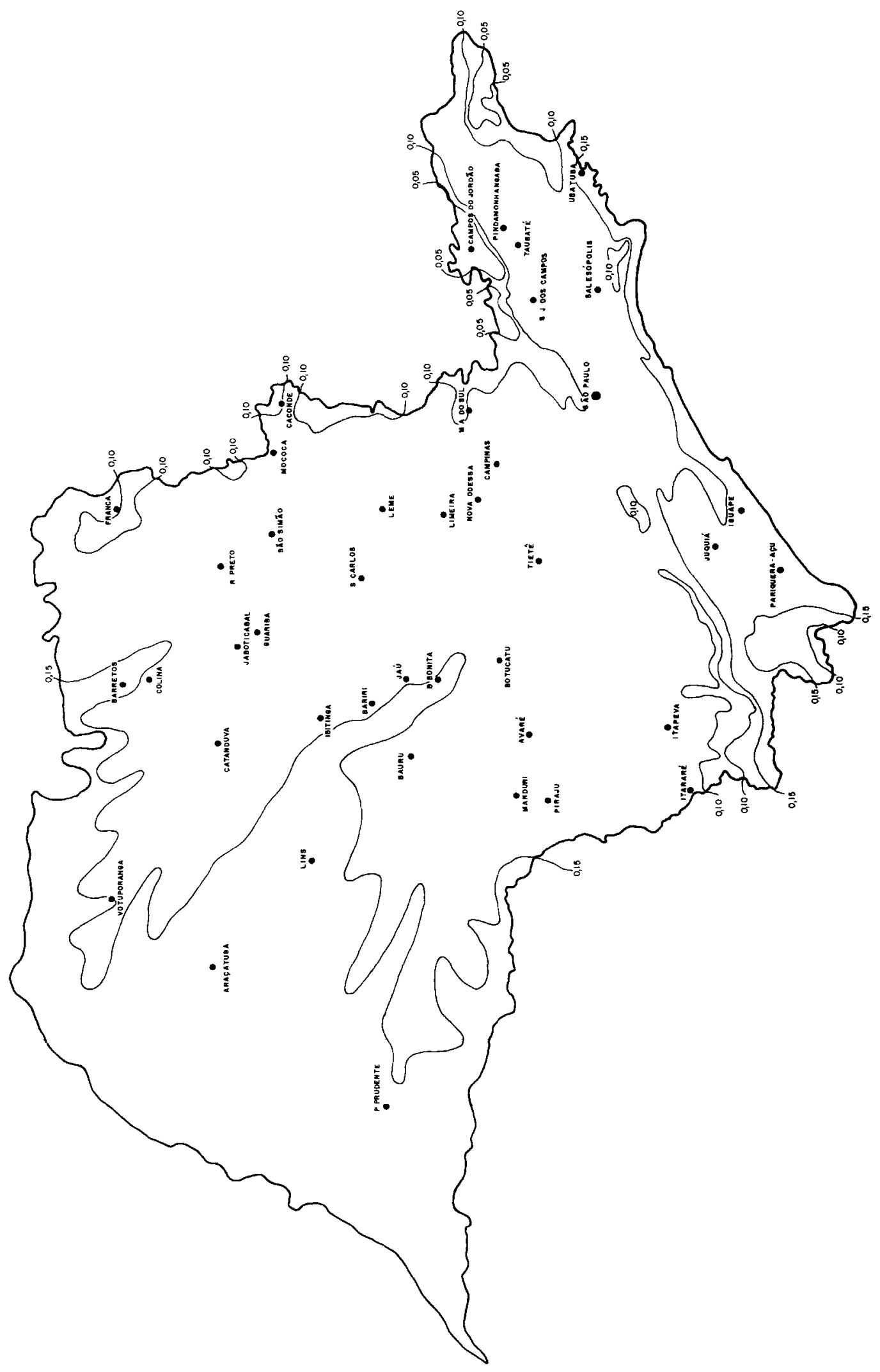


Regionalização do ICC - Em razão das variações nos valores de ICC durante o inverno e o verão, entre as localidades, analisou-se a variação espacial do ICC médio, considerando-se duas estações distintas de crescimento das forrageiras: verão (outubro-março) e inverno (abril-setembro).

Para fins de regionalização do Estado, indicando o potencial de produção de matéria seca durante os períodos de verão e inverno, mapearam-se os valores de ICC correspondentes a essas duas estações de crescimento.

Em vista da pequena densidade de pontos, efetuou-se o mapeamento mediante as correlações entre ICC de verão ou ICC de inverno com a altitude do local. Os coeficientes de regressão encontrados, respectivamente, 0,89 e 0,83 , permitiram o uso desta técnica de mapeamento.

A figura 2 apresenta as isolinhas de ICC de verão para o Estado, notando-se os maiores valores $(>0,35)$ na região litorânea, no Vale do Ribeira, no Norte e Oeste. Esses valores diminuem nas regiões montanhosas $(<0,25)$.

A figura 3 mostra as isolinhas de ICC de inverno, época mais crítica da produção de forrageiras. $\mathrm{Na}$ região central do Estado, o índice varia de 0,10 a 0,15 ; no Norte, é superior a 0,15 e, na região da Serra da Mantiqueira, inferior a 0,10.

Segundo Pedreira (1973), durante a estação de pastejo, é necessária uma taxa diária de acúmulo de matéria seca de $12 \mathrm{~kg} / \mathrm{ha} / \mathrm{dia}$ para que uma pastagem suporte, pelo menos, um bovino de $350 \mathrm{~kg}$ de peso vivo.

De acordo com as equações de estimativa das TAMS obtidas, o valor de ICC mínimo para atender à condição acima seria de: 0,25 para colonião e jaraguá; 0,22 para pangola e 0,27 para gordura. As relaçôes entre esses valores e os encontrados permitem verificar que, durante o inverno, a produção de matéria seca pelas gramíneas forrageiras analisadas é insuficiente para o pastejo, para fins comerciais. O mesmo ocorre, durante o verão, nas partes altas das regiões serranas (Serra do Mar e da Mantiqueira).

\section{REFERÊNCIAS BIBLIOGRÁFICAS}

ABRAMIDES, P.L.G.; BUFARAH, G.; BIANCHINE, D. \& BRAUN, G. Efeito de duas alturas e três frequiências de pastejo em braquiária humidícola. Boletim da Indüstria Animal, Nova Odessa, 41:131-143, 1984.

CERVELLINI, A.; SALATI, E. \& GODOY, H. Estimativas da distribuição da energia solar no Estado de São Paulo. Bragantia, Campinas, 25(3):31-40, 1966.

FITZPATRICK, E.A. \& NIX, H. A. The climatic factor in Australia grassland ecology. In: FITZPATRICK, E.A. \& NIX, H.A. Australia grasslands, Camberra, National University Press, 1970. p.3-36.

MATTOS, H.B. \& PEDREIRA, J.V.S. Crescimento estacional de oito leguminosas forrageiras de clima tropical. Boletim da Indústria Animal, Nova Odessa, 41:145-157, 1984.

MOTA, F.S.; BERNY, Z.B. \& MOTA, J.F.A.S. Índice climático de crescimento de pastagens naturais no Rio Grande do Sul. Pesquisa Agropecuária Brasileira, Brasília, 16(4):453-472, 1981.

MOTA, J.F.A.S. Clima, lotação animal e suplementação de feno em pastagem nativa em Pelotas, Rio Grande do Sul. In: CONGRESSO BRASILEIRO DE AGROMETEOROLOGIA, 7., Viçosa, I991. Resumos. Viçosa, Sociedade Brasileira de Agrometeorologia, 1991. p.208-209.

MONTSERRAT, P.; TREIDL, R.A. \& MKTCHAN, R.S. Climate aspects of forage provision and animal production. World Meteorological Organization. CAgM - VIII Joint Rapporteurs on meteorological aspects of forage provision and animal production, 1989. $106 \mathrm{p}$.

PEDREIRA, J.V.S. Crescimento estacional dos capins colonião Panicum maximum Jacq, gordura Melinis minutiflora Pal de Beauv, jaraguá Hyparrhenia rufa (Ness) Stapf e pangola de Taiwan A-24 Digitaria pentzii Stent. Boletim da Indústria Animal, Nova Odessa, 30(1):59-145, 1973.

PEDRO JÚNIOR., M.J.; ALFONSI, R.R.; CAMARGO, M.B.P.; CHIAVEGATTO, O.M.D.P.; ORTOLANI, A.A. \& BRUNINI, O. Disponibilidade da radiação solar para o Estado de São Paulo. Instituto Agronômico, Campinas, 1989. 13p. (Boletim técnico, 129)

THORNTHWAITE, C.W. \& MATHER, J.R. The water balance. Centerton, N.J., Drexel Institute of Technology, 1955. 104p. (Publications in Climatology, v.8., n. 1) 